DOI: https://doi.org/10.47405/mjssh.v5i10.502

\begin{tabular}{|c|c|}
\hline 1. 1.54 & Malaysian Journal of Social Sciences and Humanities (MJSSH) \\
\hline $\begin{array}{c}\text { Malaysian Journal of } \\
\text { solal sciences and }\end{array}$ & Volume 5, Issue 10, October 2020 \\
\hline (MJ-SSH) & e-ISSN : 2504-8562 \\
\hline & $\begin{array}{l}\text { Journal home page: } \\
\text { www.msocialsciences.com }\end{array}$ \\
\hline
\end{tabular}

\title{
Effects of Perceived Organisational Support and Emotional Intelligence on Turnover Intention among Logistics Drivers
}

\author{
Faidatul Nadiah Hanib', Wan Arnidawati Wan Abdullah' \\ ${ }^{1}$ Department of Human Development and Family Studies, Faculty of Human Ecology, Universiti Putra Malaysia (UPM) \\ Correspondence: Wan Arnidawati Wan Abdullah (arnidawati@upm.edu.my)
}

\begin{abstract}
The turnover trends in the logistics industry are surprisingly high, regardless of the rapid growth of the industry. Turnover contributes to an impactful loss for the industry to tolerate the new recruitment costs, time consumption, performance disruption, and moral decline among employees due to the workload transfer. Previous literature presented various factors affecting turnover intention, and it could be concluded that factors within an organisation and individual play an essential role in turnover actions. Hence, this research focuses on perceived organisational support and emotional intelligence as factors to turnover intention among logistics drivers in Selangor. Eighty respondents from POS Logistics Berhad in Selangor participated in self-administered survey questions of Survey Perceived Organizational Support, Wong and Law Emotional Intelligence Scale, and Turnover Intention Scale. Results revealed that most of the respondents have a moderate level of POS (84\%) and a high level of EI (91\%). In comparison, slightly half have a low level of TOI (56\%). Research also found that POS and EI have no significant relationship with turnover intention, which is contrary to previous literature. Similarly, three criteria of EI; self-emotion appraisal, uses of emotions, and others-emotions appraisal also have no significant relationship with turnover intention. Only regulations of emotions $(\mathrm{r}=0.024$, $\mathrm{p}=0.031$ ) has significant relationship with turnover intention. Since the current study location was restricted for a few branches of Pos Logistics in Selangor, it limits the result of the study due to misrepresent the whole community fairly. Future researchers are encouraged to extend or increase the sampling size to other companies and regions to make better generalisations.
\end{abstract}

Keywords: Perceived organisational support, emotional intelligence, turnover intention

\section{Introduction}

The Malaysia Freight and Logistics Market (Mordor Intelligence, 2018) reported the rapid growth of the logistics industry since 2015 and the competitive industry of freight forwarding business, which is estimated to be worth USD 53.45 in 2017. Notwithstanding the critical demand for workforce in the logistics and distribution industry, there is a shortage of suitable or credible employees. This industry fails to attract new employees to participate in for being perceived as a low level and poor prospects career. Additionally, the turnover trends in the sector are surprisingly high, with $10 \%$ to $30 \%$ (McCormark, 2017). Malaysia similarly faced the same situation with a rate of $2 \%$ turnover (Mordor Intelligence, 2018). This turnover contributes to an impactful loss for the industry to tolerate the new recruitment costs, time consumption, performance disruption, and moral decline among employees due to the workload transfer (Grotto et al., 2017; Rehman, 2012). 
The shortage of employees in the logistics industry has created an intense situation for the remaining workers (Hussain \& Asif, 2012). With the high demand of the industry, they must struggle with the excessive workload due to the shortage of employees, high goals, and objectivity. They were emotionally and physically exhausted and tired when they need to double up their delivery services. Though taking more trips may increase their income, indirectly, it affects their productivity. Hence, equipping employees with the right support is essential to retain the logistics workers in employment. Grotto et al. ( 2017) proposed the idea of controlling turnover by creating a positive working environment, promoting job fit among employees, having supportive leaders, and helping employees managing changes.

Previous literature presented various factors affecting the turnover intention. Job dissatisfaction (Chin, 2018; Priyanath, 2018), job stress (Adan Gok et al., 2017; Islam et al., 2019), job embeddedness (Choi \& Kim, 2015; Rafiq et al., 2019), organisational commitment (Chang et al., 2019; Gatling et al., 2016), perceived organisational support (Albaqami, 2016; Alias et al., 2018; Fayaz et al., 2019), work engagement (Alias et al., 2018), work-life balance (Chang et al., 2019), individual performance (Priyanath, 2018), emotional intelligence (M. Waheed Akhtar et al., 2017; Giao et al., 2020; Hossain et al., 2017; Mendis, 2017; Trivellas et al., 2010, 2013) and leadership style (Gatling et al., 2016; Sultana \& Jabeen, 2018) have been associated with the turnover scenario. It could be concluded that factors within an organisation and individual play an essential role in turnover actions. Hence, this research focuses on perceived organisational support and emotional intelligence as factors to turnover intention.

Previous researches also have explored these relationships between perceived organisational support, emotional intelligence and turnover intention in few industries, such as logistics industries (Mendis, 2017), banking industries (Fayaz et al., 2019; Giao et al., 2020; Hossain et al., 2017), manufacturing industries (Alias et al., 2018; Chin, 2018), among academicians in higher education institutions (Albaqami, 2016; Gojeh et al., 2015; Manogharan et al., 2018; Too et al., 2015), hotel businesses (Akgunduz \& Sanli, 2017; Akova et al., 2015; Chang et al., 2019; Emiroğlu et al., 2015), among nurses (Choi \& Kim, 2015) and also among interns (Chang et al., 2019). It is relatively scarce about employee turnover in logistics companies' literature.

With the current situation of workforce shortage in the logistics industry, it is appealing to examine the influence of the perceived organisational support (POS) and emotional intelligence (EI) on the turnover intention in the logistics industry. In short, the primary purpose of this study is to describe the level of POS, EI, and turnover intention among lorry drivers and to determine their relationship.

Based on the purposes of the research mentioned, the research questions are as follows:

i. What is the level of perceived organisational support, emotional intelligence, and turnover intention among the logistics drivers?

ii. Is there any relationship between perceived organisational support, emotional intelligence, and turnover intention among lorry drivers?

iii. Is there any relationship between dimensions of emotional intelligence and turnover intention among lorry drivers?

It is necessary first to understand the scenario in order to help the organisation to improve on any deficiencies which can affect the turnover act. The company could then formulate plans, programs, activities, modules, and guidelines for the employees to increase their emotional intelligence and provide additional support as preventive measures. Furthermore, the knowledge gained could be applied within the community to establish responsiveness among organisations to cope with the challenges in retaining their workers, especially in the logistics industry. Besides, this research could also be encompassed to the Ministry of Human Resource (MOHR) and Malaysian Logistics and Supply Chain Association (MLSCA) to move towards retaining the workers in the logistics industry considering the great opportunities offered by the industry. 


\section{Literature Review}

\section{Issues of turnover and turnover intention}

According to Grotto et al. (2017), the turnover of the workforce is defined as the number of employees that quit within a given period, usually one year, with the total number of employees. Employee turnover is always costly for organisations (Mendis, 2017). It will incur the new recruitment costs as well as the training costs to provide the non-financial benefit to another employee (Rehman, 2012). The indirect price of turnover also includes the workload that will transfer to another employee, which results in the low morale of the employee and loss of social capital (Hussain \& Asif, 2012).

Employee turnover can be both whether voluntary or involuntary action. Voluntary action is when the employee decides to resign and find a better opportunity to achieve their own goals. There are many significant reasons discussed for employees to leave their position. Those are rude behaviour, work-life imbalance, inability to meet expectations, employee misalignment, feeling undervalued, lack of coaching and feedback, lack of decision-making ability, inadequate skills, organisation's instability, stagnation, lack of growth opportunities, and lack of appreciation. Meanwhile, involuntary action happened when the employee deals with poor performance or the organisation confront a financial crisis so that they need to downsize the number of the workforce.

Mendis (2017) described the relative strength intention of an individual towards voluntary permanent withdrawal from an organisation as turnover intention. The turnover intentions of employees can disturb the development process of an organisation. Turnover intention is a mental decision prevailing between an individual's approach concerning a job to continue or leave the job (Hussain \& Asif, 2012). It is described as a cognitive process of thinking, planning, and has a desire to leave the job. Someone may have a desire to leave the company, but yet there is something that prevents them from leaving. Turnover intention usually occurred when employees received less support from the organisation. Even though they have performed well in the company, they did not get any recognition and other financial or non-financial rewards.

\section{Perceived organisational support and turnover intention}

According to Perryer, Leighton, \& Travaglione (2010), perceived organisational support (POS) could be defined as general beliefs the employees have about the support given by their organisation. The support is perceived in terms of the recognition, value, and care of their well-being. The concept of social exchange can be the norm of reciprocity that results from the relationship between an employee and an employer.

Previous works of literature have discussed that POS could increase their productivity to help the organisation in reaching the goals and objective, and indirectly reduce the intention of the employee to turnover (Kalidass \& Bahron, 2015; Perryer et al., 2010). POS can create a sense of obligation among employee to repay to the organisation through the organisational support theory (Arshadi, 2011; Kalidass \& Bahron, 2015; Perryer et al., 2010). Meanwhile, if the organisation did not provide appropriate support, they were likely to be less committed to the organisation and move to another organisation. Vice versa, if they feel the organisation acted positively towards them, they will remain with the organisation (Hussain \& Asif, 2012).

Most research showed a negative relationship between POS and turnover (M. Waheed Akhtar et al., 2017; M Waheed Akhtar et al., 2017; Hussain \& Asif, 2012; Kalidass \& Bahron, 2015; Koodamara, 2014). Koodamara (2014) stated that the role of POS and perceived supervisor support could lead to turnover intention, which both acted as antecedents. He found that POS is not a crucial predictor of turnover intention. However, POS becomes significant when the support from the supervisor becomes low. The high level of POS can promote belongingness towards the organisation and indirectly can reduce the intention to turnover. 
Thus, the company needs to understand the need of the employees to create a supportive and motivating company policy. If the employees feel that their contribution is not being valued, their behaviour or attitudes will reveal their intention to turnover. The problems of tardiness and absenteeism (Arshadi, 2011) could be some of the effects of turnover intention.

\section{Emotional intelligence and turnover intention}

Emotional intelligence (EI) is the ability to recognise, understand, and manage our own emotions during a critical situation that might influence the feeling of others. It also can drive our behaviour and attitude that can impact people negatively or positively. Emotional intelligence, which is an intrinsic part of an individual (Bande et al., 2015), has been widely acknowledged to contribute towards their well-being. Previous literature proved the relationship between EI and related organisational outcomes such as job performance, job satisfaction, turnover intention, turnover, organisation commitment, and leader-member exchange (LMX) (Trivellas et al., 2010, 2013).

According to Wong \& Law (2002) and Mayer and Salovey (1997), there are four dimensions of EI which includes;

i. self-emotion appraisal (SEA): the ability to understand their deep emotions and be able to express these emotions naturally;

ii. regulation of emotion (ROE): the ability to regulate their emotions and enable more rapid recovery from psychological distress;

iii. others-emotion appraisal (OEA): the ability to perceive and understand the feelings of those people around them; and

iv. use of emotions (UOE): the ability of individuals to make use of their emotions by directing them towards constructive activities and personal performance.

These four dimensions recognised the significance of EI in understanding one's own emotions and managing it to avoid upsetting or insulting one's and others' feelings. Having high EI can decrease the plan to turnover act because they feel that other people will appreciate and do not manipulate it for their goodness. EI can be used in building up a strong relationship between employee and employer to decrease the turnover rate in the organisations. It is believed that emotions are very useful in gathering information that helps one person to discover and understand the social environment. This understanding will ease them to cope with the situation itself. The employees will be more engaged with their work and have less intention to quit when the employees are emotionally intelligent.

A low level of turnover intention is continuously associated with the high level of EI (Giao et al., 2020; Saeed et al., 2014). Employees that have a high EI usually have a lower level of intention to quit from their position. Mohammad, Aun, Law, and Wigin (2014) stated that organisations could construct EI to reduce turnover, identify transformational leaders, improve organisational culture, stimulate creativity, and enhance employee acceptance of the radical change. Past research showed that EI is used to determine the job outcomes of the employee in the organisation in several variables, such as organisational commitment, job performance, and job satisfaction. Corporate culture has also been used to determine whether EI can be affected or not by it, which may influence the intention of the employee to turnover (Mohammad et al., 2014). The results showed that an organisation with a good quality culture could lead to high EI among leaders to train and aspire to their subordinates. Thus, it could offer a better result, and the turnover intention will be lower. It means that the plan to leave among the employees will be smaller and indirectly can cut the cost of management as well as can increase productivity in performing their job.

\section{Methodology}

This study is a quantitative research using survey research design and statistical analysis to investigate social phenomena. A set of questionnaires in the dual language, Malay and English as the medium of communication, was developed by the researchers to measure the POS, EI, and turnover intention. The 
questionnaire consists of two parts. Part A consists of a background of workers such as length of services and income, and Part B consists of survey instruments of POS, EI, and turnover intention.

POS is measured through the 36-items survey of perceived organisational support (SPOS) that was developed by Eisenberger et al., 1986. Besides, Wong and Law Emotional Intelligence Scale (WLEIS) developed by Wong and Law (2004) was used to determine the EI. WLEIS consists of 16 items with four scales; self-emotions appraisal, regulations of emotions, use of emotion, and others-emotion appraisal. These two instruments used Likert's seven-point scale 1 to 7 to measure, and the ranking is $1=$ strongly disagree to $7=$ strongly agree. While for turnover intention, the 15 -items of Turnover Intention Scales (TIS) developed by G. Roodt (2004) was applied to determine the level of their intention to leave the organisation. TIS used a five-point response of scale and the sample like "how often have you considered leaving your job?".

This study is descriptive and correlational research intends to describe the level of POS, EI, and turnover intention among lorry drivers in the logistics industry. Correlation can be either direct indirect. A direct or positive correlation means as one variable changes in value, the other change in the same direction. Conversely, indirect or negative correlation implies as one variable changes in value, the other changes in the opposite direction. Thus, the correlation research is suitable to determine the relationship between independent variables (POS and EI) and the dependent variable (turnover intention) among workers. The data obtained were analysed using IBM SPSS Statistics 22. Mean score and one-way ANOVA were used to test the hypothesis in the research questions.

Logistics drivers from Pos Logistics Malaysia, one of the companies that involve in the logistics industry, were selected as the respondents of the study. A stratified sampling technique involving three branches under Pos Logistics Selangor; Shah Alam, Port Klang, and Rawang, was used to attain the adequate quantity for analysing data. Eighty drivers ranged from 24 to 56 years old have participated in this study despite the required sample of 103 employees, as proposed by Krejcie \& Morgan (1970) table. A majority of 57 respondents $(71.3 \%)$ have served for less than ten years as a lorry driver. In terms of income, more than half (53.8\%) received a salary between RM1200 to RM3000, while 31 $(39 \%)$ received below the minimum wage of RM1200. Only six respondents have an income of more than RM3001.

\section{Result and Discussion}

Findings show that almost all respondents $(84 \%)$ were in the moderate level of POS; only five respondents $(6 \%)$ were at a low level. Eight respondents $(10 \%)$ were at a high level. While for EI, nearly all respondents (91\%) showed a high level of EI, and another $9 \%$ showed a moderate level of EI. None of the respondents showed a low level of EI. In contrast, a very minimal number of respondents have a high level of turnover intention. Only three respondents $(3.8 \%)$ responded to have a high level. In comparison, more than half (56\%) respondents showed a low level, and 32 respondents $(40 \%)$ were at the medium level of turnover intention.

\section{Perceived organisational support and turnover intention among lorry drivers}

The research established that there is a weak negative relationship between the POS and turnover intention among lorry drivers but not significant $(\mathrm{r}=-0.030, \mathrm{p}=0.791)$. This finding means that lorry drivers who were not fully supported by their organisation will lead to turnover. As we know that if the organisation cannot value the employees' contribution and low support in employee well-being, it can lead to turnover. Previous studies showed the significant negative relationship between perceived organisational support and turnover intention (Muhammad Waheed Akhtar et al., 2017; Arshadi, 2011; Hussain \& Asif, 2012; Kalidass \& Bahron, 2015; Koodamara, 2014). This study supported the previous literature; however, it failed to prove its significance of the negative relationship. 


\section{Emotional intelligence and turnover intention among lorry drivers}

The research established that, in general, there is no significant relationship between emotional intelligence and turnover intention among lorry drivers $(\mathrm{r}=0.196, \mathrm{p}=0.081)$. This null hypothesis was failed to be rejected apparently because most people hide their real feeling; that is why they did not give a good response. Focusing on the four dimensions of EI, only the regulations of emotions dimension were observed to have a significant positive relationship with turnover intention among lorry drivers $(\mathrm{r}=0.241, \mathrm{p}=0.031)$. This finding indicates that a person who can regulate their emotions will have more rapid recovery from psychological distress. While for other dimensions of EI, the results could not prove a significant relationship.

The finding which reveals that there is no significant relationship between the uses of emotions and turnover intention ( $\mathrm{r}=0.0218, \mathrm{p}=0.052)$ among lorry drivers is contrary to Trivellas et al. (2013). They proved the negative relationship between the use of emotions and turnover intention. The use of emotions is the ability to utilise their feelings that can lead them toward personal performance and productive activities (M Waheed Akhtar et al., 2017). This ability can improve them in decision making, cultivate creative thinking, and improve persistence against challenging tasks (Trivellas et al., 2013). The inability to use their emotions properly to improve their performance will lead to a lack of motivation to strive to achieve their targets and company goals. It will later indirectly lead to turnover from their current job.

The result also shows that there is no significant relationship between others-emotions appraisal on turnover intention among lorry drivers $(\mathrm{r}=0.022, \mathrm{p}=0.846)$. This relationship indicates that people can perceive and understand the emotions of those people around them. People who are high in this ability will be much more sensitive to the feelings and emotions of others as well as reading their minds.

Besides, there is a negative relationship, but not significant, between the self-emotions appraisal and turnover intention $(\mathrm{r}=-0.06, \mathrm{p}=0.957)$. The value of $\mathrm{r}$ is negative, which indicates a person that has low sensitivity in acknowledging their emotions has a possibility to turnover. This finding is consistent with previous works of literature, which found that people who have an exceptional ability will sense and acknowledge their emotions well before most people (Trivellas et al., 2013).

\section{Conclusion}

The current study focuses on the effect of POS and EI on turnover intention among workers in the logistics industry. This study was only limited to one company of the logistics industry in Klang Valley, which involved only 80 drivers. This small coverage may not reflect the turnover intention among workers in the logistics industry. Future researchers are encouraged to extend or increase the sampling size to other companies and regions to make better generalisations. Furthermore, this study uses self-reporting by which respondents may respond positively about themselves to avoid undesirability. Hence, social desirability bias may skew reporting.

There are several implications of the study that could be drawn. The present study had contributed to the existing literature on the field of POS, EI, and turnover intention. This study found that the regulation of emotion among lorry drivers has a significant relationship with turnover intention. Employees must regulate their emotions to prevent from any turnover drives.

This present study has provided more information for an organisation and governments to understand and handle the problems or factors that can influence the drivers to turnover. Organisations can use the result to formulating plans, programs, activities, modules, and guidelines to retain the drivers and build a good relationship between them. The organisation also could plan an intervention program or training to boost up the level of emotional intelligence of drivers in handling and managing their emotions in the right way. The intervention program needs to involve all the employees from top-level management to lower-level management to help, retain, and build a strong relationship between them. As a result, it can help employers to be fair to employees and make them feel appreciated and more loyal to the 
company. Through these strategies it can help both parties to be able to build the most substantial relationship and make a win-win situation.

Moreover, by understanding the current trend of turnover intentions among drivers, it helps the government to minimise the possibility of drivers to turnover, especially for the Ministry of Human Resource (MOHR) and Malaysian Logistics and Supply Chain Association (MLSCA) to take action. Furthermore, the government can promote or raise awareness among the organisations to taking care of their employees from top-level management to lower-level management. Next, it can help them to understand the emotions of drivers to cope with the challenges in maintaining the employees and give more support towards them to retain the drivers.

\section{References}

Adan Gok, O., Akgunduz, Y., \& Alkan, C. (2017). The effects of job stress and perceived organizational support on turnover intentions of hotel employees. Journal of Tourismology, 3(2), 23-32. https://doi.org/10.26650/jot.2017.3.2.0003

Akgunduz, Y., \& Sanli, S. C. (2017). The effect of employee advocacy and perceived organizational support on job embeddedness and turnover intention in hotels. Journal of Hospitality and Tourism Management, 31, 118-125. https://doi.org/10.1016/j.jhtm.2016.12.002

Akhtar, M. Waheed, Ghufran, H., \& Fatima, T. (2017). The effect of emotional intelligence on turnover intentions; the role of employee well-being, engagement and perceived organisational support. Jinnah Business Review, 5(2), 69-80. https://doi.org/10.4172/2168-9601.1000243

Akhtar, M Waheed, Shabir, A., Safdar, M. S., \& Akhtar, M. S. (2017). Impact of emotional intelligence on turnover intentions: The role of organizational commitment and perceive organizational support. Journal of Accounting \& Marketing, 06(04), 259. https://doi.org/10.4172/2168-9601.1000259

EI has a negative relationship with TI

Akhtar, Muhammad Waheed, Shabir, A., Safdar, M. S., \& Akhtar, M. S. (2017). Impact of Emotional Intelligence on Turnover Intentions : The Role of Journal of Accounting \& Impact of Emotional Intelligence on Turnover Intentions: The Role of Organizational Commitment and Perceive Organizational Support. December, 0-7. https://doi.org/10.4172/2168-9601.1000259

Akova, O., Cetin, G., \& Cifci, I. (2015). The relation between demographic factors and the turnover intention in pre-opening hotel businesses. Procedia - Social and Behavioral Sciences, 207, $377-$ 384. https://doi.org/10.1016/j.sbspro.2015.10.177

Albaqami, A. (2016). Determinants of turnover intention among faculty members in Saudi public universities [Univeristy of salford]. In ProQuest Dissertations and Theses. http://usir.salford.ac.uk/40542/

Alias, N. E., Rohmanan, N. H., Ismail, S., Koe, W.-L., \& Othman, R. (2018). Factors influencing turnover intention in a Malaysian manufacturing company. International Conference on Economics, Business and Economic Education 2018, KnE Social, 771-787. https://doi.org/10.18502/kss.v3i10.3171

Arshadi, N. (2011). The relationships of perceived organizational support (POS) with organizational commitment, in-role performance, and turnover intention: Mediating role of felt obligation. Procedia - Social and Behavioral Sciences, 30, 1103-1108. https://doi.org/10.1016/j.sbspro.2011.10.215

Bande, B., Fernández-Ferrín, P., Varela, J. A., \& Jaramillo, F. (2015). Emotions and salesperson propensity to leave: The effects of emotional intelligence and resilience. Industrial Marketing Management. https://doi.org/10.1016/j.indmarman.2014.10.011

Chang, H. P., Hsieh, C. M., Lan, M. Y., \& Chen, H. S. (2019). Examining the moderating effects of work-life balance between human resource practices and intention to stay. Sustainability (Switzerland), 11(17), 4585. https://doi.org/10.3390/su11174585

Chin, C. L. (2018). The influence of job satisfaction on employee turnover intention in the manufacturing industry of Malaysia. Journal of Arts and Social Sciences, 1(2), 53-63.

Choi, J. S., \& Kim, K. M. (2015). Job embeddedness factors as a predictor of turnover intention among infection control nurses in Korea. American Journal of Infection Control, 43(11), 1213- 
1217. https://doi.org/10.1016/j.ajic.2015.06.017

Emiroğlu, B. D., Akova, O., \& Tanrıverdi, H. (2015). The relationship between turnover intention and demographic factors in hotel businesses: A study at five star hotels in Istanbul. Procedia Social and Behavioral Sciences, 207, 385-397. https://doi.org/10.1016/j.sbspro.2015.10.108

Fayaz, M., Amin, K., \& Khan, N. (2019). Factors affecting employees turnover intentions in Khyber Pukhthunkhwa-Pakistan (A case study of Habib Banks Limited, Peshawar Region). SSRN Electronic Journal, 1-14. https://doi.org/10.2139/ssrn.3438115

Gatling, A., Kang, H. J. A., \& Kim, J. S. (2016). The effects of authentic leadership and organizational commitment on turnover intention. Leadership and Organization Development Journal, 37(2), 181-199. https://doi.org/10.1108/LODJ-05-2014-0090

Giao, H. N. K., Vuong, B. N., Huan, D. D., Tushar, H., \& Quan, T. N. (2020). The effect of emotional intelligence on turnover intention and the moderating role of perceived organizational support: Evidence from the banking industry of Vietnam. Sustainability, 12(5), 1857. https://doi.org/10.3390/su12051857

Gojeh, L. A., Ayde, A., \& Fantahun, A. (2015). Staff development and training on turnover pattern and retention in academic libraries of Ethiopian universities. Journal of Library and Information Sciences, 3(1), 1-32. https://doi.org/10.15640/jlis.v3n1a1

Grotto, A. R., Hyland, P. K., Caputo, A. W., \& Semedo, C. (2017). Employee turnover and strategies for retention. In H. W. Goldstein, E. D. Pulakos, J. Passmore, \& C. Semedo (Eds.), The Wiley Blackwell Handbook of the Psychology of Recruitment, Selection and Employee Retention (First, Issue April 2017, pp. 443-472). John Wiley \& Sons Ltd. https://doi.org/10.1002/9781118972472.ch21

Hossain, S. M. K., Roy, M. K., \& Das, P. K. (2017). Factors affecting employee's turnover intention in banking sector of Bangladesh: An empirical analysis. ASA University Review, 11(2), 103116.

Hussain, T., \& Asif, S. (2012). Is employees ' turnover intention driven by organizational commitment and perceived organizational support? Journal of Quality and Technology Management, 8(2), $1-10$.

Islam, N., Zeesan, E. A., Chakraborty, D., Rahman, M. N., Uddin Ahmed, S. I., Nower, N., \& Nazrul, T. (2019). Relationship between job stress and the turnover intention of private sector bank employees in Bangladesh. International Business Research, 12(8), 133-141. https://doi.org/10.5539/ibr.v12n8p133

Kalidass, A., \& Bahron, A. (2015). The relationship between perceived supervisor support, perceived organizational support, organizational commitment and employee turnover Intention. International Journal of Business Administration, 6(5), 82-89. https://doi.org/10.5430/ijba.v6n5p82

Koodamara, N. K. (2014). Role of perceived organizational support and organizational justice on employee turnover intentions: a literature review. International Journal of Management and Social Science Research Review, 1(5), 106-112.

Krejcie, R. V, \& Morgan, D. W. (1970). Determining sample size for research activities. Educational and Psychological Measurement, 30, 607-610.

Manogharan, M. W., Thivaharan, T., \& Abd Rahman, R. (2018). Academic staff retention in private higher education institute - Case study of private colleges in Kuala Lumpur. International Journal of Higher Education, 7(3), 52-78. https://doi.org/10.5430/ijhe.v7n3p52

McCormark, L. (2017). No Title. Transport \& Logistics Turnover \& Hiring Trends. https://www.peoplestreme.com/blog/transport-logistics-employee-turnover-infographic

Mendis, M. V. S. (2017). The impact of reward system on employee turnover intention: A study on logistics industry of Sri Lanka. International Journal of Scientific \& Technology Research, 6(9), $67-72$.

Mohammad, F. N., Chai, L. T., Aun, L. K., \& Wigin, M. W. (2014). Emotional intelligence and turnover intention. Intrnational Journal of Academic Research, 6(4), 211-220. https://doi.org/10.1201/b12752-17

Mordor Intelligence. (2018). Malaysia Freight and Logistics Market (2019-2024).

Perryer, C., Leighton, C., \& Travaglione, A. (2010). Predicting turnover intentions : The interactive effects of organizational commitment and perceived organizational support. August. https://doi.org/10.1108/01409171011070323 
Priyanath, H. M. S. (2018). Factors affecting on tendency in employee turnover. Fourth Annual Student Research Session- 2018, July, 47-.

Rafiq, M., Wu, W., Chin, T., \& Nasir, M. (2019). The psychological mechanism linking employee work engagement and turnover intention: A moderated mediation study. Work, 62(4), 615-628. https://doi.org/10.3233/WOR-192894

Rehman, S. (2012). Employee turnover and retention strategies:An empirical study of public sector organizations of Pakistan. Global Journal of Management and Business Research, 12(1), 83-89.

Saeed, I., Waseem, M., Sikander, S., \& Ridzwan, M. (2014). The relationship of turnover intention with job satisfaction, job performance, leade member exchange, emotional intelligence and organizational commitment. International Journal of Learning \& Development, 4(2), 242-256. https://doi.org/10.5296/ijld.v4i2.6100

Sultana, S., \& Jabeen, S. (2018). Bridging the relationship of transformational leadership and turnover intentions with mediating effect of employee engagement. InTraders International Trade Academic Journal, 1(1), 2660-4408. https://doi.org/10.1093/imamci/dnt037

Too, E. K., Chepchieng, M. C., \& Ochola, J. (2015). Effect of academic staff retention on quality education in private universities in Kenya. In Problems of Education in the 21st Century (Vol. 64, Issue 2004, pp. 86-94).

Trivellas, P., Gerogiannis, V., \& Svarna, S. (2010). The impact of Emotional Intelligence on job outcomes and turnover intention in Health Care. Journal of Psychology, 59, 321-325.

Trivellas, P., Gerogiannis, V., \& Svarna, S. (2013). Exploring workplace implications of emotional intelligence (WLEIS) in hospitals: Job satisfaction and turnover intentions. Procedia - Social and Behavioral Sciences, 73, 701-709. https://doi.org/10.1016/j.sbspro.2013.02.108 